\title{
Can brokers rig the real estate market? An exploratory study of the commercial real estate sector
}

Article

Accepted Version

McAllister, P. (2020) Can brokers rig the real estate market? An exploratory study of the commercial real estate sector. Journal of Property Research, 37 (3). pp. 254-288. ISSN 14664453 doi: https://doi.org/10.1080/09599916.2020.1794935 Available at https://centaur.reading.ac.uk/92060/

It is advisable to refer to the publisher's version if you intend to cite from the work. See Guidance on citing.

Published version at: https://doi.org/10.1080/09599916.2020.1794935

To link to this article DOI: http://dx.doi.org/10.1080/09599916.2020.1794935

Publisher: Taylor \& Francis

All outputs in CentAUR are protected by Intellectual Property Rights law, including copyright law. Copyright and IPR is retained by the creators or other copyright holders. Terms and conditions for use of this material are defined in the End User Agreement.

$\underline{\text { www.reading.ac.uk/centaur }}$ 
Central Archive at the University of Reading

Reading's research outputs online 
Can brokers rig the real estate market? An exploratory study of the commercial real estate sector 


\begin{abstract}
This paper focuses on how brokerage practices in the markets for commercial real estate investment assets and residential development land in England generate different possibilities for and patterns of opportunistic behaviours. Drawing upon previous research and analysis, the paper examines the nature of the brokerage market in both sub-markets. An interactionist model of the determinants of ethical judgement in the context of the brokerage sector is created. Based upon an interview survey of brokers and principals, the findings of an exploratory empirical study are discussed. Whilst there are challenges in defining, observing and measuring opportunistic behaviours, it is concluded that a number of different unethical practices have become routine rather than exceptional in the markets for institutional-grade real estate assets and residential development land.
\end{abstract}




\section{Introduction}

Capturing the principal-agent costs in dealing with intermediaries and advisors, in Shakespeare's Much Ado About Nothing Claudio advised "Let every eye negotiate for itself. And trust no agent..." In the UK and in the majority of major international real estate markets, investment agents ${ }^{1}$ are key intermediaries in the commercial real estate market. In 'good' years, including bonuses, apparently some of the top real estate agents in the large London-based global brokerage firms can earn between $£ 5$ million and $£ 10$ million $^{2}$. Monitoring transactions of more than $\$ 10$ million, Real Capital Analytics (RCA) estimate that, in the UK, real estate transaction volumes have on average been $£ 60$ billion per annum in the period 2015-2019. Assuming brokerage fees of 1\%-1.25\% for buyers' and sellers' agents, this represents an annual revenue stream of $£ 600$ million- $£ 750$ million. Additional RCA data suggests that the brokerage sector is becoming more concentrated as the 'Big Five' ${ }^{3}$ real estate advisory firms account for the majority of the institutional grade commercial real estate brokerage activity globally. However, with a significant weighting given to the quality of transaction processes (incorporating quality of pre-sale information, bidding process and professional standards), the UK was ranked top of JLL's Global Real Estate Transparency Index in 2018. By international standards, in the UK ad valorem brokerage fees are low, transaction times tend to be amongst the fastest and turnover rates are relatively high (see Devaney et al, 2017 and 2019).

If the word dealers is replaced with brokers or agents, Bloomenthal's description in 1960 of the overthe-counter market in securities resonates with the nature of trading in the contemporary commercial real estate investment market.

The over-the-counter market has no shape nor form. It is a desultory, unorganized, illdefined market completely dependent on the whims, views, and decisions of thousands of dealers with no common denominator other than the profit motive. There is no central reporting agency and no way to determine the extent of a day's transactions in a particular security except in retrospect, and then inadequately. (Bloomenthal, 1960, 199).

Direct ${ }^{4}$ investment in commercial real estate assets typically incurs relatively high, non-tax transaction costs due largely to the private and decentralised nature of the market and the heterogeneous nature of

\footnotetext{
${ }^{1}$ The terms agents and brokers are used interchangeably here. Broker is more widely used in the US whilst agent is more widely used in the UK.

${ }^{2}$ Information on remuneration tends to be private and sensitive. I have been told this information by someone that I trust who has worked at the heart of one of the large global real estate advisory firms. ${ }^{3}$ RCA identify CBRE, JLL, Cushman \& Wakefield, Colliers International and (Newmark) Knight Frank as the major global firms. It is estimated that in 2018 they collectively had a $60 \%$ market share of transaction brokerage for institutional grade real estate assets.

${ }^{4}$ Direct investment refers to purchase of actual real estate assets. It is distinct from investment in listed and unlisted funds or companies that own real estate assets. In some cases, the distinction can be difficult to make - especially in cases where investment in a single building occurs through a Special Purpose Vehicle.
} 
the assets. The largest tangible component of these non-tax transactions costs is brokerage fees. Compared to listed securities, the attributes of the commercial real estate market increase search and matching costs and are also associated with extended transaction times. Brokers are expected to add value by reducing these costs. However, the incompleteness of brokerage contracts may also enable intermediaries to extract through opportunistic behaviours a substantial proportion of any added value.

In all major commercial real estate markets across the globe, transactions rarely take place without at least one, often two, brokers (see Devaney et al, 2017). Brokers employ their private knowledge of 'the market' to span the information gap between potential buyers and sellers. Brokers can make positive contributions to informational and allocative efficiency in asset markets. From a micro-economic perspective, Chan (1983) proposed that, given information asymmetry and search costs, without intermediaries a potential lemons market problem can emerge. Intermediaries serve as information production agents about the qualities of investments and, thus, facilitate improved allocative and informational efficiency. The less informed that buyers are, the more that sellers will find it in their interests to offer fewer desirable assets leading to the deterioration in the quality of the assets offered. Hence, the improvement in efficiency created by intermediaries is limited by the proportion of wellinformed buyers and the size of information costs of the other buyers. However, as the discussion below highlights, the information asymmetry between intermediaries and principals generates further moral hazard problems and potential for opportunistic behaviours.

There is little documented knowledge about the detail of how commercial real estate brokerage operates in different markets. Devaney et al. (2017) analysed real estate transaction and brokerage processes as place and path dependent outcomes of regulated, institutionally mediated socio-technical systems interpreted at a local level through market devices and reproduced by human actors and social structures. Comparing many global markets, they identified a nuanced and intricate pattern of market conventions with local market outcomes reflecting local adaptations and modifications of a small number of common brokerage models. A key dichotomy was between markets where a double brokerage model dominated compared to markets where only the seller was represented by a broker.

In the context of the English real estate market, the focus of this paper is on differences in local brokerage practices between the commercial real estate investment market and the market for residential development land. The paper explores how the different brokerage structures between (and within) the two real estate sub-markets generates different possibilities for and patterns of opportunistic behaviour by brokers. Drawing upon previous research and analysis, the next section discusses the nature of the brokerage market in both sub-markets and reviews the literature on the topic. Much of this literature has drawn upon theoretical frameworks from micro- and institutional economics. The subsequent section outlines an interactionist model of the determinants of ethical judgement in the context of the 
brokerage sector to illustrate the range of personal, organisational, regulatory etc. variables that can affect ethical outcomes. This is followed by a discussion of research methods and the findings of the empirical research which is based upon a survey of brokers and principals using semi-structured interviews. Finally, a concluding section draws out the key issues and implications of the research.

\section{Market Context and Previous Research}

Devaney et al. (2017) outlined the range of services that brokers in commercial real estate markets provide for their clients. In practice, sellers of commercial real estate assets expect their brokers to be able to provide intelligence about and implementation of the optimal method of sale and marketing. Sellers typically want advice on the most likely buyer, the best approach to marketing, the likely sale price, the appropriate terms and conditions of any sale and the reliability of potential buyers in terms of transaction execution. Although not all commercial real estate markets are double-brokered, for buyers, their brokers similarly provide advice, information and intelligence on what assets are on the market (or, even better, what assets will soon be on the market or assets that are being discreetly sold 'offmarket'), competing buyers, a seller's particular preferences and concerns, the expected risks and returns from the asset and optimal negotiation and/or bidding strategies. If problems emerge in the due diligence process, brokers often have to mediate (to get the deal 'over the line') as well as assist in the execution of the transaction. In situations where there is no apparent desire to sell or buy a specific asset, brokers can also instigate transactions through 'creative agency'. Drawing upon, often difficult to obtain, knowledge of who is actively buying, what they are looking to buy, how much they are prepared to pay and who owns what assets, brokers can match buyers and sellers. Some individual brokers can exert considerable market power by effectively excluding other brokers and even potential buyers from key information networks in what are often thinly traded markets. There are stories, perhaps apocryphal, of particularly powerful brokers who practically instruct their clients that they should be selling or buying a specific asset.

Most of these brokerage roles are also found in the development land market. However, there are some notable differences. There is much more specialisation of brokerage functions in the land market. The large, London-based multi-service advisory firms tend to dominate the market for brokerage services for the sale of large lots of development land. These development agents ${ }^{5}$ tend to specialise in selling and act mainly for land owners selling mainly through informal tender. Given that nearly half of the

\footnotetext{
${ }^{5}$ There is no consistent terminology. The term 'land agent' is sometimes used to describe managers of rural estates but also sometimes used to describe intermediaries in the land market who can act for buyers and sellers of development land. The term 'development agent' is commonly used to describe an intermediary in the land market who typically acts for either buyers or sellers of development land.
} 
new dwellings are built by the ten largest house builders, the buyer market is also dominated by a relatively small number of firms (see Archer and Cole, 2016). The double brokerage model is not as prevalent as in the investment market and it is not standard practice for buyers, especially the volume house builders, to appoint agents to advise them when bidding for land. The house builders seem to be confident in their own expertise in evaluating sites and executing transactions. Again, in contrast to the commercial investment market, there is also more specialisation in terms of brokers 'introducing' sites to potential buyers. Such 'intro agents' tend to specialise in identifying development sites at various stages in the 'planning pipeline' introducing them to developers in return for a fee. In many cases (but by no means always), the intro agent will have formed a relationship with the land owner without necessarily being formally retained to represent the land buyer.

In the course of the research ${ }^{6}$, respondents provided lots of anecdotes about the operation of the commercial real estate brokerage sector where its particular vocabulary of 'whispers', 'earlies', 'last calls', 'double dipping', 'landing lights' 'inside tracks', 'sharpening pencils', 'winding up', 'runners', 'having a position', 'ramping' etc. was often used. (See Appendix 1 for a glossary). In a transaction, sellers' brokers acquire information and intelligence that is valuable to potential buyers, buyers' brokers and for future transactions. They gain information about which buyers are taking a serious interest in an asset that is for sale. They find out what will appeal or not appeal to their client e.g. commitment to complete a transaction speedily, concern about 'price-chipping', proof of availability of funds etc. Consequently, particularly for commercial assets, they can give favoured buyers' brokers (potentially lucrative) advanced knowledge - termed an 'early' - that an asset is about to be offered for sale (typically in exchange for a similar 'early' in future transactions). An early is potentially lucrative in the English real estate investment market because there is a widely observed convention that the first agent to introduce an asset for sale to a potential buyer will act as broker for that buyer if it results in a transaction. This 'first past the post' system is discussed further below.

In order to make a transaction smoother, an 'early' can be conditional upon the broker 'introducing' the asset to whoever is expected to be (by the selling broker) the most likely buyer. This practice is essentially broker rigging so that a transaction may become more akin to a stage-managed performance rather than a fully competitive sale process. After other bids have arrived, the seller's broker can tell a favoured buyer's broker what offer their client needs to bid to secure the asset or land (commonly termed the 'the last call' or 'the last shout'). Sellers' brokers can assure their client of the reliability of one buyer over another in executing a transaction and make sure that their preferred buyer is 'top of the list'. As noted earlier, in a bidding process, sellers' brokers will also obtain valuable information about

\footnotetext{
${ }^{6}$ Some of the description of the operation of the brokerage sector here draws upon knowledge gained during the research as well as existing literature.
} 
the identity, the preferences and the pricing of the unsuccessful bidders which can be used in exchange for similar information and to instigate transactions by matching unsuccessful bidders with other sellers. ${ }^{7}$ In comparison, buyers' brokers have less to offer within the limits of a single transaction. Crucially, they are in a position to influence the bid price of their client. Further, given that there is little specialisation ${ }^{8}$ in terms of buying and selling brokerage in the commercial real estate market, the buyer's broker in a transaction will usually become the selling broker in later transactions and be in a position to return any favours ('earlies', 'last calls' etc.) received when they were acting for a buyer.

In the English commercial real estate market, assets are usually transacted either 'off-market' or 'onmarket'. On-market transactions typically involve an informal ${ }^{9}$ tendering process (commonly termed 'best bids'). In order for buyers' brokers to earn a commission, they usually have to be the first to 'introduce' the asset for sale to the ultimate buyer. Perhaps rather obviously, this requires access to two critical pieces of market intelligence - that the asset is for sale and the identity of the most likely highest bidder. Buyer brokers who are earliest to be informed that that an asset is for sale have, what is effectively, a 'front-running' advantage helping them to get to the most likely buyer first ${ }^{10}$. 'Off market' transactions typically involve discreetly marketed 'one-to-one' transactions where the buyer is offered an exclusive opportunity to purchase an asset on a non-competitive basis. Typically, such transactions occur when the potential buyer is a 'special purchaser' 11 or when the seller does not want 'the market' to know that they are selling assets and/or what price they are selling assets for. However, in practice,

\footnotetext{
${ }^{7}$ Writing about Eastdil Secured, a largely US brokerage firm, Adam Pincus described this point very well writing... "While the winning bid on any given deal is the one that matters most in the moment, the so-called bridesmaids, or the losing bidders, are also hugely important to most investment sales brokers. The reason is that once a bidder tries in earnest to win a deal, the seller's broker knows exactly what they can pay and exactly what kind of asset they want. This inside information feeds on itself, providing Eastdil and their main competitor, CBRE, a continuing advantage in the marketplace for the biggest deals"

${ }^{8}$ In the English commercial estate market, a notable exception to this pattern is Eastdil Secured. In this market, Eastdil specialise in selling assets and arranging real estate finance. They have a significant presence in London. When selling, there have been rumours (possibly originating from competitors) that Eastdil may pressure buyers to secure finance through Wells Fargo (the owner of Eastdil Secured) or use Eastdil to arrange financing. Adam Pincus also referred to this criticism.

${ }^{9}$ An informal tender involves interested buyers submitting bids in writing by a specified time and date. The seller does not have to accept the highest or any offer. For the buyer, their offer is not legally binding until contracts are signed after a period for legal and technical due diligence.

${ }^{10}$ In the Netherlands, Nelen (2007) refers to this type of advantage from the perspective of developers. He states that "[O]nce a project developer or real estate agent is able to receive this kind of information earlier than his competitors, he has a major head start. It is obvious that in such a cultural setting key players are inclined to push back frontiers in order to obtain access on time to vital information. Of course, close contacts between real estate agents and high ranked public and private officials may easily turn into corruption and collusion." More recently in the UK, there has been some concern about the undue influence from planning consultants, development agents and ex-politicians acting as lobbyists for developers on current politicians (see Booth and Jones, 2018 and Booth, 2018).

${ }^{11} \mathrm{~A}$ special purchaser is formally defined by the International Valuation Standards Committee as a particular buyer for whom a particular asset has special value because of advantages arising from its ownership that would not be available to other buyers in a market. Typically, it is the owner of a neighbouring asset or legal interest where value can be added by merging the interests.
} 
the distinction between off and on-market transactions can be less clear-cut and more blurred. For instance, in so-called targeted marketing campaigns, a small number of potential buyers (3-4) may be invited to bid without wider marketing of an asset. Outside of the UK, there have been several highprofile scandals involving collusion by real estate fund managers, brokers and other professionals over the last two decades.

In 2004, the so-called 'Frankfurt real estate scandal' involved a whole range of fraudulent activities including buyers and sellers of real estate assets engaging the services of real estate brokers after the sale has been agreed and then splitting the brokers' commissions among themselves. It was also suggested that bribes were paid among fund management organisations to corruptly influence the outcome and level of bids in sales transactions. In 2007-8 in the Netherlands, the Philips pension fund experienced fraudulent real estate transactions involving internal asset managers agreeing relatively low values for assets with external valuers, before properties were sold at below market prices to business connections. The properties were then later 'flipped' for the market value, with the price difference being divided between the participants (see Van de Bunt and Wingerde for a full discussion over the scandal). Of course, these examples are fairly extreme and probably rare. In reality, individual and organisational self-interested actions will tend to be more subtle and nuanced.

Nelen (2007) analysed some of the characteristics of the Dutch commercial real estate market that facilitated such fraudulent behaviour characterising it as a

“...closed circuit, which is hard to obtain access to for outsiders; strong internal ties, old boys networks, frequent contacts on a one-to-one basis, and reciprocity. Many business relations are made and maintained at informal meetings and places, like golf courses, restaurants and real estate fairs (such as the PROVADA in the Netherlands or the MIPIM in Cannes, France). Important business deals are 'precooked' during these meetings and vital information is shared with other key players on a reciprocal basis: one can expect one's business associates to give one vital information in return, now or in due time. Sometimes, tacit deals are made to 'stay out of each other's hair', but to keep one another informed on relevant developments in the industry."

It is likely that many of these features would be recognisable to participants in the UK's commercial real estate market.

Whilst there is limited research on brokerage in the commercial real estate market, there is a longstanding and substantial body of work on the micro-economics of brokerage markets in the residential sector (see Nanda et al, 2016 for an overview). Largely dominated by US-based researchers investigating US markets, the focus of much of the research has been on efficiency of different residential brokerage models, the costs and benefits of professional regulation, competition and market concentration in the residential brokerage sector, the performance of various listing methods and commission structures. Often with large, rich data sets, typically the outcomes of interest have been 
transaction costs, time-on-market, brokerage firm performance and the effects of different brokerage arrangements on transaction prices. Whilst comparatively little attention has been paid to the complexities, nuances and impacts of human interactivity on the operation of residential real estate markets, an exception is Halpern (1996) who focussed on the impact of friendship between residential brokers on prices and transaction times. In this research, the hypothesis tested was whether, when brokers were friends, increased trust and altruism would lead to smoother and faster transactions prices. Whilst the results were inconclusive, it was found that increased regulation of the sector was reducing the importance of business friendships in the residential brokerage sector analysed.

There is a fairly longstanding body of literature for the residential sector that identifies potential benefits from brokerage representation such as shorter time on market, higher probability of sale and the possibility of price uplifts (see Yavas, 1994). However, benefits crucially depend on the extent of principal-agent issues. Theoretical studies by Zorn and Larsen (1986) and Yavas and Colwell (1999) model the contract structures of US residential brokers. This work reveals a mismatch between the interests of the principal and agent that is created by typical contracts and incentive structures. However, this does not mean that, in practice, agents act against the interests of their principals.

Yet empirical research suggests that information asymmetries may lead to principals being poorly served. Levitt and Syverson (2005) and Rutherford et al. $(2005$; 2007) examined data on residential sales and found that brokers selling their own homes behaved differently than when selling their clients' homes. Controlling for location, characteristics, market conditions etc., these studies found that agents' own houses sold for more than the houses owned by their clients. Levitt and Syverson also found that agents' houses stayed on the market almost 10 days longer on average. The conclusions of these studies were blunt. Levitt and Syverson concluded that the commission structure and brokers' information advantage leads to homeowners being advised to sell too quickly and for too low a price. In a similar study, Rutherford et al. (2005) also concluded that the commission structure leads to agents expending too little effort for their clients. More recent research from Singapore confirms and extends the findings to the behaviour of agents when buying houses. Agarwal et al. (2019) find strong evidence to suggest that real estate brokers exploit their information advantages when buying houses for themselves paying around $2.5 \%$ less for their houses relative to comparable houses bought by non-broker buyers. Distinguishing between the ability to cherry pick cheaper houses more effectively than non-broker buyers and enhanced bargaining power over "distressed" or "weak" sellers who brokers are able to identify, they attribute most of the price effect to the enhanced bargaining power of brokers.

However, there are significant differences between commercial and residential real estate markets. In the commercial sector, the assets are more complex, transaction sizes are much larger, value determinants differ, decisions are typically investment-driven rather than consumption-driven and 
transaction participants (i.e., buyers, sellers, brokers) are usually financially sophisticated. Consequently, a commercial real estate broker's role may differ somewhat from that of residential brokers. Focussing on commercial real estate, Schofield (2018) draws upon Burt's model of 'structural holes' to investigate the role of commercial real estate brokers as information intermediaries in commercial real estate transactions in New York and London. Drawing upon network theory, a broker is conceptualised as an intermediary that depends upon their social capital to broker the flow of knowledge (gained from their networks) between relatively disconnected principals. In the context of real estate markets, structural holes are mainly caused by the intrinsic features of these markets; asset heterogeneity, information asymmetry and spatial fixity. Commercial real estate assets vary in quality, attributes, market conditions and the natures and preferences of buyers and sellers which leads to variable but pervasive information asymmetries and imperfections. Spatial fixity intrinsically embeds commercial real estate assets in local markets and, consequently, local market knowledge is important. Schofield and Devaney (2015) argue that a double (or differentiated) brokered transaction is conducive to information capture and control by brokers. Given the information asymmetries outlined above, the double brokerage model embeds strategically important market knowledge in the hands of intermediaries, away from seller and buyer. This knowledge may enable them to capture a high proportion of the efficiency gains generated by their intermediation.

Social ties can both encourage and discourage unethical behaviours. They may facilitate exchange and discourage opportunistic behaviour in some contexts. In line with Burt's structural hole theory, social ties act as "conduits of knowledge between individuals, mechanisms for enforcement of performance expectations, and catalysts for discovering new economic opportunities" (Collins, Uhlenbruck and Rodriguez, 2009, 91). Deeper social ties should then increase the rate of interactions between actors, build trust between the actors and facilitate information exchange. However, in many professional services there is little transparency in these interactions and trust generated from repeated interactions can lead some intermediaries to collude in self-dealing.

Closely linked but without drawing explicitly upon network theory and concepts such as structural holes, there has been a body of work by Louis Halbert with others focussing on the role of real estate brokers (as participants in transcalar territorial networks) in facilitating and shaping the 'landing' of global capital in international real estate markets. As "anchoring agents", it is argued that brokers design and diffuse the indicators, representations and narratives necessary for investment decisions (Halbert and Rouanet, 2014). Emphasis is placed on the social capital possessed by these information intermediaries through their professional, personal and community networks. As noted above, brokers' access to private information allows them to, in effect, reduce transaction uncertainty for buyers and sellers. More broadly, it has been argued that firms that engage in unethical behaviours seek to reduce 
the uncertainty in their environment. Rodriguez et al. (2005) argued that engaging in corruption can often be vital to reducing uncertainty for firms and that such actions are particularly likely when managers believe that corruption is a common, widely understood practice. In essence, professional networks can generate sometimes unethical behaviours that are viewed as providing acceptable solutions to managerial problems. These solutions can then become institutionalised in the occupational subculture of the profession (DiMaggio and Powell, 1983). Hence, certain unethical behaviours may become institutionalised or routinised practices helping individuals to justify their actions

In the UK commercial real estate market, McAllister, Hughes and Gallimore (2008) identified concern among investors about opportunistic behaviour by commercial real estate (mainly buying) brokers caused by incentives created by the outcome-based remuneration. Essentially, since brokers only received a commission when bid price was accepted and the transaction executed, brokers are incentivised to encourage the clients to bid optimistically. However, they also found that there were important disincentives to opportunistic behaviour. It was concluded that institutional buyers tended to be alert to the brokers' incentives, were relatively well-informed about market conditions and, consequently, were in a position to critically evaluate the quality of information, advice and intelligence provided by agents. They identified other significant controls on opportunistic behaviour. Investors tended to rely on brokers with whom they have built up trust. Brokers have strong incentives to develop long-term relationships in order to generate repeat and related business and to preserve or generate a good reputation. However, the sector has had some problems and the last five years have also seen increased professional regulation of the commercial real estate brokerage market.

In 2014, the Investment Property Forum's (IPF) introduced a Protocol on Open Market Investment Agency. This followed a period of growing disquiet within the London-based investment and brokerage community about 'double dipping' and multiple introductions by the large multi-service real estate advisory firms. In that year, a number of articles was published in Property Week (basically a trade magazine for professionals in the commercial real estate market) reflecting and expressing concern about the practices of some leading (albeit un-named) brokerage firms. In a speech at the Britain's Best Agents Awards dinner in February 2014. Nick Leslau (a leading real estate investor and former investment agent) summarised the views of some leading fund managers stating

I can't address a group of investment agents without raising a truly significant problem, which in my view represents a matter so serious that it could extend to undermining the entire professional investment agency world: conflict management. In my view the same firm cannot act for a seller and multiple buyers at the same time. It is inconceivable that conflicts will not arise, however high you build your Chinese walls. To deny that is to show a lack of understanding of human nature. Your world is now a minefield, as the number of smaller agencies dwindles and the big guys increasingly dominate. It will only take one major incident to blow up, and this could spell disaster for the industry. As a buy-side client I really don't like it because who knows how a deal is being 
carved up internally and it only takes one tiny suspicion to destroy a trust built up over many years. (Leslau, 2014)

In response, the Mother's Bunch Club (a monthly lunch club of about a dozen of London's leading investment agents formed in 1972) took unusually prompt action to address these concerns. Under the auspices of the IPF, the protocol mentioned above was quickly drawn up. The protocol acknowledged that:

"The potential for conflict of interest has become a fact of modern investment agency. Such situations should always be managed proactively and transparently to ensure trust and confidentiality is maintained at all times." (Investment Property Forum, 2014)

Common governance themes are outlined in the protocol focusing on clarity and fairness in terms of engagement, maintenance of conflicts of interest databases and reference to complaints-handling procedures and redress schemes. Most of the protocol is concerned with multiple introductions (where multiple individual agents in a single firm 'introduce' an asset to multiple potential buyers) and dual agency (where individual agents from the same firm as the seller's agent acts also for the buyer).

The protocol emphasises the role of a maintaining a barriers policy that seeks to ensure that deal teams from within the same firm acting for different clients on the same transaction have strict separation of information flows. James Watson - a member of the Mother's Bunch Club - bluntly acknowledged problems commenting that the protocol was "cleaning up dual agency which has become a mucky area and something that we as a profession have lost credibility on. There's been some sharp practice in the past that we need to address." In 2017, the RICS subsequently released a Professional Statement on conflicts of interest in investment agency that addressed similar issues. For instance, dual agency (acting for both buyer and seller is severely frowned upon), multiple introductions to multiple buyers are acceptable as long as the broker is transparent with the client but individuals within a firm should not act for competing buyers. Further incremental advice is acceptable as long as the agent is transparent with the client and suitable internal information barriers are created. Since the issue of dual agency and multiple introductions has been exposed and (self) regulation has improved, these specific problems seemed to have become less prevalent.

A recent analysis by Hatfield, Kominers and Lowry (2019) has tried to explain how real estate brokerage could be affected by collusive (brokerage fee) pricing. Their modelling is underpinned by the presumption that, in double brokerage markets, (buyers' and sellers') brokers need to cooperate to execute transactions. In particular, brokers who compete on the price of their brokerage services may be excluded from transactions and information networks rendering the value of "price-deviators" services less valuable to buyers and sellers. The threat of such punishment enables brokers to extract 
rents and a large fraction of total surplus generated by their intermediation. Using an experimental methodology, Price, Robinson and Seiler (2018) concluded that "trusted brokers" could influence prices by privately communicated signals particularly when the private signal conveys a price above a reference point implied by recent transactions of similar product. Reflecting the importance of execution risk to some sellers, it was also concluded that sellers require a significant price premium for execution risk associated with a buyer who is less likely to complete the transaction compared to a buyer who is highly likely to complete the transaction.

One of the few large-scale empirical studies of price effects of brokerage in the commercial real estate market was carried out by Ling, Naranjo and Petrova (2018). Drawing upon a large sample of transactions comprising industrial, multi-family and office commercial real estate assets in the US and using a hedonic pricing methodology, they found that on average buyers who pay for brokerage representation pay significantly higher prices. They attributed this finding to incentive that brokers have to convince buyers to shut down their search too quickly and, as a result, pay higher prices. Whilst the results were not completely consistent when disaggregated by sector and geographically, they also found that representation by a selling broker was associated with lower prices. They concluded again that this result was consistent with brokers having a strong incentive to convince sellers to conclude their search for a buyer too quickly and, as a result, receive lower prices. Providing additional evidence to them that commercial real estate buyers are ill-served by brokers, they also estimate that, all else equal, the sale price is $11.1 \%$ higher when both buyer and seller employ the same brokerage firm. Consistent with their hypothesis that non-broker transaction prices may be lower due to investors sharing the cost reduction associated with not paying brokerage fees, they found that multi-family and office properties sales that do not involve a broker transact at significantly lower prices, with discounts varying from $6.2 \%$ (for multifamily) to $13.5 \%$ (for office).

Ling et al.'s findings have attracted little attention despite their potentially major implications for the commercial real estate brokerage sector. It is possible that their econometric model is biased by omitted variable issues. Transactions involving buyers and/or sellers without broker representation may not be typical of all transactions. For instance, some buyers may make very attractive and unsolicited offers to owners directly. There is then a potential endogeneity issue with certain transaction types affecting whether brokers are instructed and the pricing. Ling et al's, perhaps surprising, findings have not been replicated in other research in the commercial real estate sector. In the residential sector, whilst the overwhelming conclusion drawn by empirical studies has been that brokers do not add value, there is little evidence of systematic price effects. 
Employing sales data on transactions involving multifamily assets from the Atlanta and Phoenix markets, Hardin et al. (2009) did not find evidence to support the existence of systematic, differential transaction pricing outcomes due to the presence of brokers. Focussing only on the New York market and, therefore, drawing upon a smaller sample, the findings of Devaney and Scofield (2017) were much less dramatic but also less consistent than Ling et al (2018). Although the result was not statistically significant in all models, the coefficient on the broker variable was negative in all cases in their research. In contrast to the results of Ling et al. (2018) they found that, when a broker was used by the buyer, price per square foot was lower. Similarly, when a seller appointed a broker, higher prices per square foot appeared to be achieved. Broadly, their results are consistent with either benefits to buyers and sellers from using brokers or no price effects.

Despite the fact that the residential land market has been controversial with claims of 'land banking' and 'land hoarding', there has been very little research focussed on the role and behaviour of brokers in the residential land market. There have been two qualitative studies based on interview surveys. McNamara (1984) investigated the role of 'intermediate agents' in the residential development process. Most relevant to this study, he found a 'double reward' or 'secondary commission' for agents arising from a 'gentleman's agreement' between a house builder and agent on the sale of the completed dwellings over and above the normal commission obtained from the original land sale. Also drawing upon an interview survey, it was the "complex networks of agents, developers and land users" in residential land markets identified by McNamara $(1984,111)$ that was partly the focus of more recent research by Adams, Leishman and Watkins (2012). Focussing on relationships, mutual interests and reputation in transactions, they were interested in roles of trust, reciprocity, collaboration, complementary interdependence, reputation, communication and an orientation towards mutual gain in such networks. In particular, they identified the importance of relationships between house builders themselves with land agents, land owners and local authorities in acquiring land on and off-market. As noted earlier, with regard to development agents, they found that the large London-based agents were key intermediaries who were subject to a 'growing audit culture'. They also emphasised the importance of local agents in complementing the sourcing of land from the larger practices.

Housebuilders thus know they must strike a balance between reliance on the large Londonbased agents who provide a well-established network that can be tapped into at a price, and the development of their own independent networks of local contacts from which sites with less well developed potential can be sourced, usually at lower cost. (Adams et al., 2012, 715)

In summary, supporting anecdotal evidence there is a body of research suggesting that commercial real estate brokers often have incentives to behave opportunistically and unethically. This may be reflected in the variable prevalence of specific unethical practices. There is some empirical evidence to suggest 
that this may have systematic effects both time-on-market and prices. However, for the commercial real estate market, in particular, the results are by no means consistent and are likely to be contingent upon brokerage arrangements and market context. Before reporting on the results of some exploratory, qualitative research into the ethical behaviour of commercial real estate brokers in the UK, the concept of ethical behaviour is briefly discussed and an interactionist model of the determinants of ethical judgement is presented below in order to illustrate the wide range of personal, organisational, regulatory etc. variables that can affect ethical judgements.

\section{Modelling the Determinants of Broker Ethical Behaviour.}

Defining the concept of ethical behaviour raises often dense issues in moral philosophy that have been debated for millennia. In a wide-ranging review of research in ethical decision-making in management, Tenbrunsel and Smith-Crowe $(2008,552)$ recognised "the seriousness of a fundamental definitional problem within the field of ethical decision making". Whilst acknowledging that the concept is contested and complicated usually with "no possibility of proof or disproof, just disagreement", the underpinning supposition in the context of this research is one of moral universalism incorporating an intrinsic set of ethical values (Graham, 2004, 5). This presumption of universal values implies that "[W]e all know, in most cases, what the morally acceptable alternatives are, and we know what sorts of actions are morally unacceptable' (Gert, 1984, 532). Closely linked to integrity, 'good' ethical behaviours tend to be described in terms of other knotty concepts such as fairness, honesty and harm prevention which are key pillars of "ordinary morality" (see McFall, 1987).

For this research, the concept of professional morality is also pertinent. This concept derives from specific professional roles consisting of the, sometimes tacit, moral obligations to which professionals should adhere because of their specialist knowledge, roles, business environment etc. (Martin, 1981). In a business context, morality can be both instrumental and non-instrumental. Rather than just doing the right thing simply because it's the right thing (non-instrumental ethics), Quinn and Jones (1995) analyse professional morality as a form of instrumental ethics creating reputational capital that can help to solve imperfections in the operation of markets related to trust deficits and co-ordination problems.

However, it is recognised that real-life, concrete situations can sometimes be too complex to apply general moral principles and that evaluation of ethical behaviour is sometimes problematic for even the perfectly moral judge. Wiggins $(2006,277)$ emphasises the importance of context

"No act or practice can be assessed as right or wrong, good or bad, etc., without the full specification of circumstances and context (context embracing, in some versions, the identity of agents).'” 
It is these contextual nuances that can sometimes be critical when evaluating professional morality. Since a precise definition of ethical behaviour is elusive, in this context a rather pragmatic approach is adopted focussing on practices that are likely to be regarded as unethical by market participants and the wider community.

Drawing upon Trevino's (1986) interactionist model of ethical decision-making in organisations, the conceptual model presented below (see Figure 1) represents the determinants of unethical behaviour as the product of the balance of effects of a range of internal and external variables on brokers, buyers and sellers. Whilst the focus is mainly on brokers, it should be noted that both brokers and principals in a transaction have a complex range of incentives and disincentives to behave ethically. Whilst some of the main incentives and disincentives for the brokers have already been discussed, it is worth bearing in mind that sellers will generally be incentivised to obtain the highest price and to collude with their brokers in various forms of unethical behaviour e.g. broker rigging. Buyers may collude with their brokers' unethical practices in order to gain advantages from insider information provided by sellers' brokers and/or opportunities to pre-empt the highest bids. Hence, collusion purely between brokers is not necessarily the main arena for unethical behaviour in a commercial real estate transaction.

For all principals and brokers, the economic importance of the transaction is a key situational factor determining the extent of their motivation to engage in unethical behaviour. The relative importance of a specific transaction can vary substantially among brokers, principals and over time. As noted above, there are a range of incentives and counterincentives for principals to encourage broker to engage in unethical behaviours. Where brokers are colluding with each other, the degree of principals' knowledge regarding market conditions and the asset will affect their ability to evaluate the behaviour of their brokers and determine the risk of discovery of any unethical conduct.

There can be a complex range of incentives and counterincentives for brokers who are trying to balance possible losses from unethical behaviour due to reputational damage, harm to business and personal relationships and even potential litigation risk against possible tangible and intangible gains. A successful outcome can result in tangible fee income and intangible benefits such as improved relationships and reputation (more social capital). Receiving such benefits is dependent on the transaction being executed.

Brokers' expected costs and benefits are then 'refracted' through a range of situational and individual moderating variables that can affect the outcome in terms of unethical behaviour. In turn, there are expected to be complex causal relationships and interactions between some of the moderating variables themselves. As illustrated in Figure 1, the main moderating variables are expected to be: - 
- Individual attributes: Internal or dispositional factors are one of the range of determinants of the extent of unethical behaviour. There are a wide range of individual traits that can affect the degree of ethical behaviour. In the auditing literature, the main focus has been on variations in the level of moral reasoning among individuals (see Trevino, 1986). Windsor and Ashkansay (1995) identified three categories of individual - autonomous, pragmatic and accommodating - who, it is proposed, respond in different ways to incentives. In addition, whilst it can be difficult to quantify, risk aversion can be important factor in many settings including individual decisions about engaging in unethical behaviour.

- Client attributes: As noted above, the clients of brokers also have motives to urge or pressurise brokers to engage in unethical behaviour, and in doing so, behave unethically themselves. Of course, any propensity towards unethical behavioural by the client will be affected by the client's individual and organisational attributes. Buyers are also heterogeneous in terms of the market knowledge. Typically, this is explored in the literature in terms of differences in behaviour between experts and non-experts, institutional and non-institutional or local and nonlocal investors. Broadly, non-expert buyers or sellers would be expected to have a greater degree of knowledge asymmetry between themselves and brokers and, therefore, a higher level of broker dependency and scope for opportunistic behaviour by brokers. Such buyers would have lower ability to evaluate the quality of advice, intelligence and information provided and the risk to the broker of discovery of unethical behaviour would also be expected to be lower.

- Market attributes: Since different business cultures have different rules and expectations regarding ethical standards, variations in ethical behaviour are to be expected (see Ahmed et al., 2003). Scale is complex with variations between countries and business sectors. The extent to which a market is regulated and the quality of external governance mechanisms is also expected to influence what are regarded as normative behaviours within a business sector. As noted earlier, in the UK most brokers (and brokerage firms) operate under a professional selfregulating model dominated by the RICS. The RICS produce numerous professional statements, codes, practice notes, information papers etc. that form a core component of the professional self-regulation of a wide range of real estate services. They tend to focus on common governance themes such as clarity and fairness in terms of engagement, maintenance of conflicts of interest databases and reference to complaints-handling procedures and redress schemes.

- Firm attributes: The quality of the ethical infrastructure of the broker's organisation and, indeed, clients' organisations, will be important moderating factors. Individuals' ethical behaviours are expected to be affected by culture of the organisation to which they belong (see Schein, 1984). A number of studies have shown that managers can substantially influence the 
ethical behaviour of their staff (Brown and Treviño 2006; Brown et al. 2005; Mayer et al. 2009; Walumbwa et al. 2007). Given that brokerage services display many characteristics associated with incomplete contracts, the quality of internal governance within brokerage firms is also expected to be a moderating factor.

- Asset attributes: As discussed earlier, an oft-cited characteristic of the commercial real estate market is its heterogeneity. Local markets and specific asset classes can vary significantly in terms of their transaction activity. The greater the level of transaction activity, the more homogeneous the assets traded and the greater the transparency of the market, the better informed both principals and brokers will be about the marginal investor(s) and likely prices. Assets can also vary in terms of their complexity. For instance, aging assets with a high number of tenants with lots of potential lease expiries will, all else equal, have more price (and appraisal) uncertainty. For less transparent and traded markets or more complex assets, it is expected that the extent of broker dependency (and scope for opportunistic behaviour by brokers) will be higher.

Given the wide range of determinants, Figure 1 suggests that patterns of ethical outcomes may be variable and intricate. Previous research has found that groups of individuals can both share and vary in their ethical reasoning and moral intent along individual, social and organisational dimensions (see Granitz, 2003). Drawing upon the limited explicit and detailed knowledge of market practices and potential unethical practices in brokering commercial real estate asset and housing land markets, the research outlined below investigates in an exploratory manner the operation of these markets and potential opportunistic behaviours by brokers. 
Figure 1 An Interactionist Model of the Determinants of Ethical Outcomes

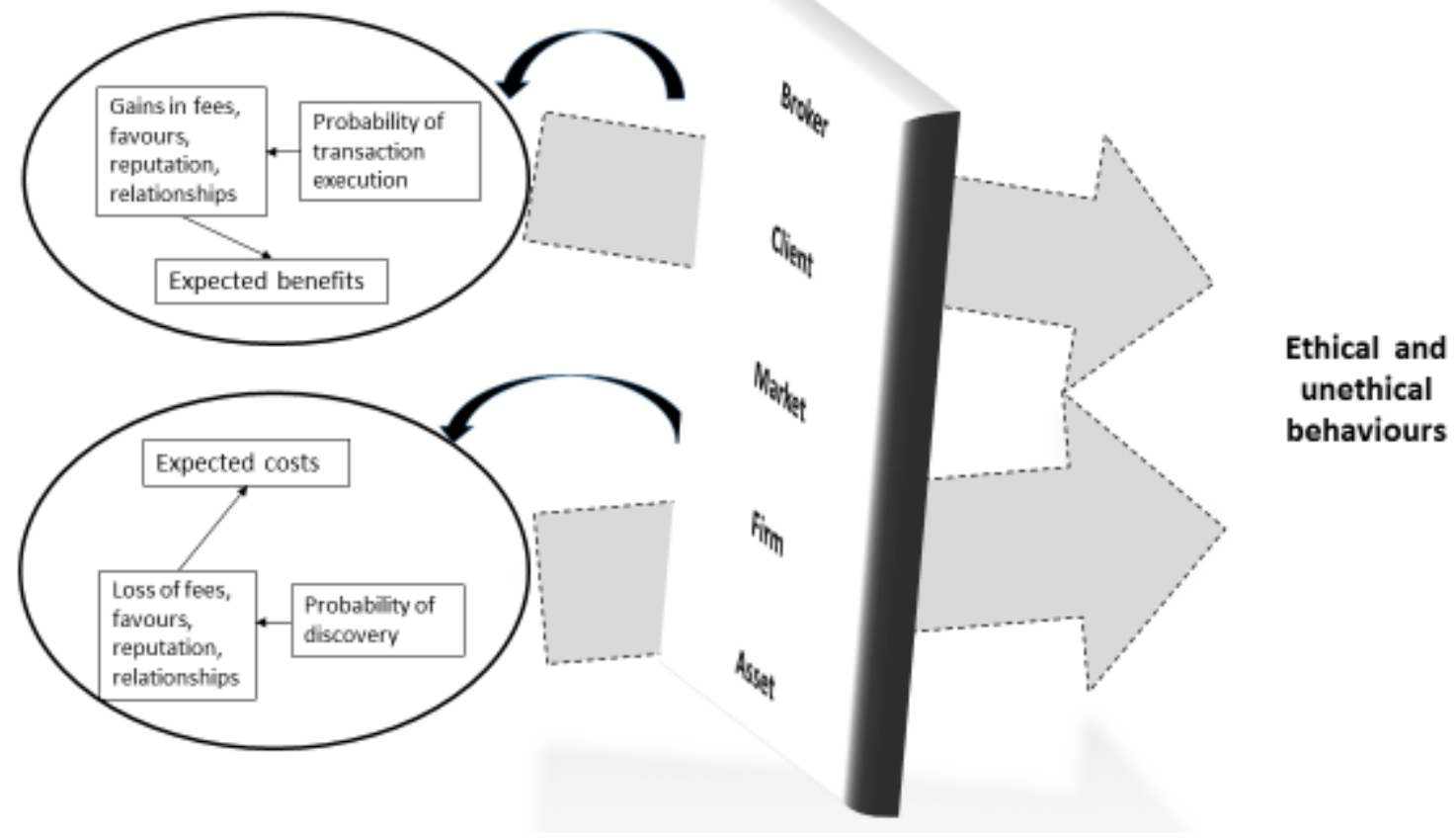




\section{Research Methods}

This research was initially informed by, what was effectively, anecdotal gossip with professional contacts. As already noted, it is essentially exploratory. It was further informed by a review of the limited literature (especially on the operation of residential land markets) on the topic. Although these sources of information generated some pre-conceptions, the aim was not to test formally the validity of pre-conceived hypotheses. Rather it was mainly concerned with discovery about market processes and participant behaviours. The research is trying to identify and assess the nature and prevalence of specific behaviours and practices in the operation of the commercial real estate investment and residential land markets. The aim was to gather evidence to address the question "What happens in practice?" whilst recognising that the term 'practice' can cover a variety of specific contexts.

Since the subject of the research was expected to involve some complex and weakly understood behaviours and relationships, it was considered unlikely to be effectively investigated by traditional positivist methods. The methods used in the paper essentially derive from social constructionism involving an interpretivist approach that tries to capture individuals' subjective perspectives and the interactions between them. The markets in land and commercial real estate assets are conceptualised as institutions developing and adapting through a process of socially constructed bundles of social norms and conventions, established exchange relationships, information networks and formal and informal rules (Hodgson, 2002). Hence

"[W]hat we call a market is always a system of social interaction characterized by a specific institutional framework, that is, by a set of rules defining certain restrictions on the behavior of market participants" (Vanberg, 1986, 75)

As Healey $(2006,151)$ points out “...market behaviour is itself 'socially constructed' by the active work of networks of actors in the development and investment process". From an economic sociological standpoint, individual market configurations and sets of practices can be viewed as

'...very much of their own making, organisationally, technologically and on the level of agency and action...Complete with strong insider-outsider distinctions, membership criteria, and interiorised forms of monitoring and regulation' (Knorr-Cetina, 2012,122124).

Qualitative techniques can be useful in developing knowledge about poorly understood areas often having an exploratory-discovery orientation. The application of qualitative research methods in this context was not to test the validity of pre-conceived hypotheses regarding the operation of the commercial real estate and housing land markets. It was mainly concerned with discovery about processes and perceptions. However, it should be acknowledged that some pre-conceptions were the 
basis for the initial set of interview questions and that a clear-cut distinction between testing preconceived hypothesis and exploration/discovery does not always exist.

There are particular methodological challenges involved in research related to ethical behaviour in business and many other contexts. A number of issues confound research on unethical behaviour. These are summed up by... "It is difficult to define, difficult to observe, and difficult to measure." The subject areas tend to be inherently sensitive; individual and organisational behaviours can often be highly context-specific; and the potential distorting effects of interviewer or social desirability bias are commonly perceived to be particularly problematic (see Brand, 2008). Since it is rare to be able to directly observe unethical behaviours, researchers have tended to rely on various survey instruments often limiting the ability to generalise.

In terms of research design, semi-structured interviews were selected as the main research method in an attempt to optimise the balance between discovery and generalisability. The initial interviews were basically a 'proof of concept' process attempting to assess whether the issues raised in anecdotal conversations had validity. Drawing upon the data gathered in the initial interviews, the later interviews were adapted and further topics explored so that, whilst retaining the overarching themes, the interview questions continued to be modified and implemented in a flexible manner as the interviews progressed. In addition, the focus of the interviews reflected the different roles of participants in the commercial real estate market.

As noted above, the potential for biases associated with the interviewer, researcher, social desirability etc. need to be acknowledged. In particular, some of the brokers that were interviewed were openly concerned that issues being discussed in the interviews might damage the reputation of the sector and even lead to regulation of a largely unregulated market. Such concerns may well have biased their responses. Given the sensitivity of the research issue, there must inevitably be some reservations about the quality of the data collected and an individual researcher's objectivity in interpreting it.

Potential researcher bias is a particularly salient issue in the sampling choices in this specific research. Convenience sampling was the basic approach taken. In addition, social desirability bias may mean that respondents can tend to dismiss perceived undesirable behaviours, emphasise desirable ones and make statements that make them look good leading to potential over-reporting or under-reporting of various behaviours (Randall and Gibson 1990). Given the sensitivity of the topic, it was felt that, in order to elicit openness, it was important that respondents had a fairly high degree of trust in and familiarity with the interviewer. As a result, a high proportion of the interviews were conducted with market contacts with whom the researcher was on friendly terms. This was particularly the case with earlier 
interviews. The remainder were individuals who were recommended by these contacts. For such individuals, the contact had usually made a personal introduction on behalf of the researcher.

Nineteen interviews, each approximately one hour long, were conducted in the second half of 2019 with individuals who had experience in dealing with brokers in commercial real estate or land transactions and/or are currently or had been brokers themselves. Approximately half of the interviews had 'clientside' roles in that they worked closely with brokers in buying and selling real estate assets and had sometimes been brokers themselves earlier in their career. Again, the sample was roughly equally split between brokers and principals specialising in land and leased commercial assets. For commercial real estate assets, the respondents ${ }^{12}$ ranged from brokers in senior leadership positions with large practices (albeit not currently in the Big Five) and brokers in smaller, niche practices. A number of institutional asset managers who had been investment brokers were also interviewed. In the residential land market, the main non-broker respondents were land buyers for large and medium sized housebuilders. On the brokerage side, respondents worked for large multi-service firms (including the Big Five), had worked for large multi-service practices but were now self-employed 'intro agents'. For in-depth interviews, the literature suggests that saturation is commonly achieved after approximately six to 12 interviews (see Gubrium and Holstein, 2001; Guest et al., 2006). Given that brokerage practices in two sectors were being investigated, it was considered appropriate to increase the number of interviews. In order to elicit openness, where possible interviews were arranged in coffee shops away from the workplace and, sometimes, outside normal working hours. However, this was not possible in some cases and, always at their request or suggestion, a significant proportion of the interviews took place in office meeting rooms at the respondents' workplaces.

Given the sensitive nature of the topic, it was judged that recording interviews might inhibit the respondents in terms of the candour of their answers. Instead, with appropriate assurances about confidentiality and permission from respondents (one respondent pointed out that if their identity were revealed that they could lose their job), contemporaneous notes were taken. The material from the contemporaneous notes was 'typed up' within 24 hours of each interview. In order to group together themes emerging from the interviews, a coding framework was devised drawing upon the interview framework and other salient issues emerging from the interviews.

\section{Findings}

The discussion of the results combines the findings from the institutional real estate sector with the findings from the residential land market. In some cases, similar issues are identified in both sectors markets e.g. the prevalence of late bids. However, several of the issues identified seem to be much

\footnotetext{
${ }^{12}$ Most of the respondents had worked for a number of firms throughout their career.
} 
more prevalent in one sector compared to the other. Given that the differences and similarities between the two sectors are of broadly equal interest, the discussion is organised in terms of issues rather than by sector. Following a brief discussion of the nature of the research and the normal reassurances about confidentiality etc., the interviews tended to begin with a broad discussion of the nature of the brokerage market and the extent to which it had changed over the last two decades. When being sold on-market, in the institutional investment market there was little evidence to suggest that the established doublebroker model of both buyer and seller having separate brokers had changed. A number of respondents commented on how improvements in communications technology had increased the speed of information transfer and introductions.

The market veterans tell you that the market is totally different. It's the speed of information. Information swapping used to be face-to-face - lunches and beers. Mobile phones changed things a lot. Now it's not even email...First, it's by WhatsApp. Then there's an email. Then we get on Propex ${ }^{13}$... If you let it slip in the pub that you've had a sale instruction for something, the five hottest buyers could hear about it in ten minutes. It's that fast. Two or three get talking. They're all good mates. You find out the next day that it's been introduced to five buyers.

Broker working for specialist investment agency 2

In line with McAllister et al. (2008), whilst the 'first past the post' convention in introduction was generally adhered to, a number of institutional buyers preferred to use retained agents to handle acquisitions. However, as the next quotation indicates, the sheer number of introductions for the same property in a short space of time tells us a lot about the speed of the information dissemination process to potential buyers and between brokers.

The 'first past the post' system should change. Some major investors don't run 'first past the post'. Their introduction policy is to select their preferred agent rather than the first. They may be getting five introductions of the same property in 10 minutes.

Senior broker in multi-service real estate advisory firm

The issue of multiple introductions by different individual agents from a single firm to multiple potential buyers emerged in the interviews. The increasing consolidation of the real estate services firms had increased the importance of governance issues among the major brokerage firms in terms of introducing the same property to multiple clients and then running multiple bids for the same asset.

You can run multiple introductions. It needs to be declared. If they're running multiple bids, they need to put up information barriers. Chinese Walls. In my experience, the ability to operate information barriers is non-existent.

Broker working for specialist retail investment agency

\footnotetext{
${ }^{13}$ Propex is a commercial product providing a secure database for institutional real estate investors in which to receive, log and store all introductions
} 
One respondent referred specifically to the 'double dipping' problem that the IPF's and RICS' respective codes on investment agency attempted to deal with it in 2014 and 2017.

You had situations when the West End was flying where individuals were acting as buying agents within the selling agent's team ...It discourages bidders. You're not really getting the best price. It almost certainly happened in the West End market. I interviewed a guy from [NAME DELETED] for a post here. The guy told me that they were basically trying to control the market. You have to remember how small the West End market is. There's only about 70 transactions a year.

Senior broker in multi-service real estate advisory firm 2

It was notable that the configuration of the brokerage sector in the residential land market is notably different from the institutional market for real estate assets. Similar to the commercial real estate market, buying land without agents seems to be rare.

\section{In my career, I haven't been involved in a one-to-one deal that hasn't involved an agent. Direct deals are few and far between.}

Land director from volume housebuilder

In broad terms, in line with Adams et al. (2012), the sale of housing land was executed by the large multi-service brokerage firms who typically tended not to get involved in introductory work. One reason for their lack of engagement in introductory work was that the large house builders were prepared to bid for on-market land without the services of a buying agent. In contrast to the investment market, the double-broker model did not hold for development land sold 'on-market'. However, again in line with the findings of Adams et al (2012), housebuilders also sourced sites from their networks of more local and much smaller firms of introductory agents.

The first tier is the large agents. Our general source is the big London agents... They account for 70-80\% of sites that come to market. It's a big change. Twenty years ago, we'd still be poring over the Estates Gazette.

Senior land director for volume house builder

Normally it's the London-based multi-service firms who are instructed by land owners to promote, market and sell. We work closely with them. They won't do off-market deals. It has to be a full market exercise... We don't use agents to advise us on purchase.

Housebuilders tend to row their own boat and not have an agent... You have, what we call, independent land agents. They're normally one-man bands - chartered surveyors and estate agents. They're good little moles with strong networks. They need to be someone with a good nose. They sniff out sites with good potential, talk to the land owner and bring them to us. It's tough - feast and famine... There are also independent planning agents. They specialise in scouring planning applications trying to short-cut the cold call to the land owner. They approach the land owner to assess whether they'd be receptive to dealing with us on an off-market basis. If they are, then they introduce it to us.

Land director for volume housebuilder

Another respondent confirmed these sources of land and added a few others. 
... you get the large chains with their new homes sections. The new homes people. They'll try to get a position...Then, there's the good old-fashioned land agents. They'll know all the land owners and all the developers. They have influence... We get quite a lot of leads from consultants - planners, architects, even landscape architects and PR people.

Development director from volume housebuilder

One intro agent summed up their role implicitly as lowering the search costs of housebuilders

I do a lot of the grunt work for them. I identify sites and tell them about the planning pipeline. Most of these guys are incredibly busy. We make the phone calls. We establish that the owner is looking for $£ x$. I monitor an enormous amount of sites...It's my job to persuade the vendor. It's my job to negotiate... There's a lot of people doing what I do.

Intro agent - sole practitioner (formerly with multi-service practice)

Given that the housebuilders usually buy on-market land without broker representation and often buy land through intro agents on an off-market basis, the 'first past the post' convention does not have the same importance in the land market as it does in the market for institutional assets ${ }^{14}$. However, as discussed below, the role of introductory agents in the land market can be ambiguous especially when the 'intro agent' has built up a strong relationship with the seller in order to persuade them to sell their land to a house builder but later typically represents the house builder in the transaction.

Agents will often claim that they have a client but don't. There's some agents who'll tell the land owner that they have a relationship with the house builder. They'll claim a relationship with the land owner when they're talking to a house builder. A lot will try their luck. There's a lot of land spivs out there.

Senior land director for volume house builder

In particular, when a single broker has managed to generate an off-market transaction between a land owner and a house builder and is instructed by the house builder, there is an opportunity to involve another agent in the process who can appear to be representing the seller.

For institutionally traded commercial real estate assets, albeit it is far from transparent how information is being disseminated, getting information that an asset is for sale before other brokers is crucially important.

Getting an early, that's the ultimate aim... Someone will give you information if you give them an early back...Sometimes an early is an early. You get information. You get a head start. If you get a really good early, you can pick your buyer. It depends on how early you get the early. You never know who to believe. Then it's down to trust and relationships. That's why we have favoured relationships.

Broker working for specialist investment agency 2

\footnotetext{
${ }^{14}$ However, the volume house builders get emailed details of lots of sites. Typically, when a planning application is made for housing on a site by a land owner, independent land agents will try to introduce it to land buyers working for volume house builders.
} 
Sometimes there was an expectation that, as a condition for the early, the broker would introduce the property to a specific client.

It's reciprocal. They'll probably give 5-10 earlies. Realistically you need to be one of the first three on the list. Then I'm likely to reinforce the opportunity and persuade my client. We know who acts for who...It helps the client to get the right agent for the right client. Buyers don't want to use agents who are junior. Inexperienced. A complete [Expletive deleted] ...The most important fact in selling is choosing the right buyer who will transact. You don't want someone who 'll chip the price. Wants to pay a smaller deposit or demands a longer completion. You can't afford to remarket. You'll lose value...It's very much choreographed. Vendors want that. So do buyers. It's like a preferred bidder situation.

Senior broker in multi-service real estate advisory firm 2

You'll line it up. That happens all the time. We spend a lot of time talking about which buyers and agents to target. It's in the interest of our client to get the best advisor on board. For the seller, you have an alignment which can increase certainty, reduce execution risk and increase price.

Senior broker in multi-service real estate advisory firm

Clearly, there are a range of costs and benefits for the various parties in 'lining up' a specific buying broker. For sellers and selling agents, execution risks are reduced as cooperative behaviour between the brokers increases. Assuming that an existing relationship is in place, the buyer is more likely to be advised by a broker that they know and trust. As ever, the specific circumstances are likely to be crucial. Where there is no established relationship between the buyer and the introductory broker, it is possible that the buying broker will feel a greater sense of obligation to the selling broker compared to their client and will be more likely to collude to some degree with the selling agent and the seller.

When an agent was 'lined up' to act for the purchaser, there could be some expectation that they would encourage the purchaser to maximise their bid. As noted earlier, McAllister et al. (2008) found that asset managers were aware of the incentives ( $a d$ valorem fees, fees contingent upon transaction occurring) and disincentives (the importance of relationships for repeat business and reputational risks) for buyers' brokers to engage in ramping. Nevertheless, in the investment market, there was clear evidence that ramping remained a concern.

(On biasing bids) ... Of course we are. That's how it works. They're savvy. They're intelligent. They're not going to be pushed. People are trying to shoo people into deals all the time. Helping them with their modelling. Improving the ERVs. Generally talking them around. It comes down to relationship. Client trust. They wouldn't be persuaded by someone that they didn't know... You look stupid if you overpay. Quite quickly your reputation goes backwards.

Broker working for specialist investment agency 2

In addition to the reputational costs identified above, in line with McAllister et al (2009), asset managers tend to be aware of such broker behaviours. 
You get pushed by agents all the time. My boss used to say to me "They're winding you up. Tell them to [Expletive deleted] off" ...You often find them dicking about trying to meet your hurdle...Yeah, you always get a cash flow model. They'll change the timing of the capex. They'll be bullish on the dilaps. Like my old boss said, it goes back to being wound up.

Institutional asset manager

Other respondents emphasised the governance procedures and advisory role that controlled potential opportunistic behaviours of agents in this context.

You can have a situation where someone is trying to ramp someone into a deal on rents or voids. There's a lot of risk management, ethics policies and compliance in place. In some cases, you can influence price. In some, you can't.

Senior broker in multi-service real estate advisory firm

Ultimately the market will determine the level. You're just trying to get your client to that level. Otherwise they'll move onto to the next one and waste their time again...I have rarely found anything to be unscrupulous.

Senior broker in multi-service real estate advisory firm 2

As noted above, often framed in terms of getting the 'inside track', buyers will expect their agents to be able to provide intelligence regarding the price expectations of sellers, other specific preferences (e.g. importance of execution period) and the level of competition from other bidders. Interested buyers will attempt to gain access to private information from the selling brokers in order to gain an advantage over other potential buyers. A common theme is an (not always) implied threat to the amount of fee income given that the large multi-service advisory practices will usually be working for most institutional buyers in some capacity. However, the issue came up rarely in the investment market.

Sometimes your own clients are bidding on something that you're selling. People remind you all the time how much business they give you. They want the inside track.

Broker working for specialist investment agency 2

This may reflect the rather subdued state of the investment market when the interviews were conducted which, in turn, suggest that the inside information of selling agents is most valuable when there is a high level of competition between buyers.

It's so long since we've had a lot of competition. That's the way retail has gone. You want that scenario of people breathing down your neck.

Broker working for specialist retail investment agency

However, it was clearly an issue with large brokers selling land to volume house builder in a highly competitive market.

You often get that question "Where do we need to be?" You get that question all the time. You can't be giving developers a direct steer. They'll say "We're good clients. 
You should be helping us out." That whole guilt trip thing is bullshit. They use that line a lot of the time.

Development agent for large multi- service practice

This type of pressure to obtain information was confirmed by housing land buyers.

Information is crucial... We're getting no inside track. No heads-up. We're getting nothing. We're paying your company lots of money. We'd like a bit more help. If it's not two-way traffic, then we'll go somewhere else.

Development director for volume housebuilder

It's tough for the glossy agents. I won't pretend that it's not. Everybody wants the information from them. A good land director gets more than everybody else.

Land director for volume housebuilder

For a 'choreographed' transaction in the commercial real estate market, following an early and the inside track on the seller's preferences etc., the final piece of inside information provided to a 'lined up' buying agent could be the price that an interested buyer would have to pay to beat the highest bid to date. As discussed earlier, this is termed the 'last call' or 'last shout'. Whilst it was identified in both the markets for institutional assets and residential development land, there were a range of views about how pervasive it was in practice. It is worth noting that late bids are standard in the sales process and have become institutionalised ${ }^{15}$ since brokers have a duty to report them to clients. Quite a lot of fairly lengthy quotations are presented below. They give a sense of the intricacies of the process and the variation in views and experiences.

I don't trust the bidding process at all. I've seen it from the inside. It's a [Expletive deleted] joke. I can't say too much. We never, ever bid on time. No. God, no. We never wanted to be first. We expected them to give a steer where everyone else was. You don't want to overpay.

Institutional asset manager

There's no hard and fast rule. There's sometimes shenanigans after the deadline. It's incumbent on us to report all offers to the client... There could be different practices across the spectrum - you might want a reputation as someone who's particularly aggressive and who can get the last call.

Broker working for specialist retail investment agency

If best bids are at five o clock, I'll be calling the selling agent at 6 or 7. 'Sorry I haven't bid yet but what bids have you had?' It's the job. I have to find out what is the competition. In those situations, the relationship is terribly important.

Senior broker in multi-service real estate advisory firm 2

Some of the art of the sales agent is to know the best way to close the process...A bid deadline rarely gets met. No-one wants to be a target to be bid at. People don't like being used. Are clients always aware that there's a last call? I suspect not. It comes

\footnotetext{
${ }^{15}$ For instance, when selling land, a number of local authorities have explicit policies regarding the treatment of late bids. Typically, due to the overriding duty to obtain best value, late bids will be accepted.
} 
down to acting in the best interests of your client. The debate is how you represent the best interests of your client and the ethics around it.

Senior broker in multi-service real estate advisory firm

One broker played down the prevalence of 'the last call' pointing out to the reputational risks of being seen to operate an unethical sales process.

I don't think that's particularly prevalent. Amongst the non-active agents, there's more brinkmanship. It doesn't really go on. You don't see it. There's an accountability issue. It's a small market. If you favour people, it creates issues further down the line. Your integrity gets questioned. As soon as you try to manipulate these situations, there is a risk of losing control of a fair process.

Broker working for specialist investment agency

Broadly, similar findings were identified in the land market. However, views were more mixed. In contrast to the investment market, the overall impression was that a 'last call' was fairly common but not necessarily typical.

If I got the call for bids at 12 on a Thursday - there's no point in doing anything until Friday afternoon. I'd have a bid in at three-ish.

Intro agent

People call in after the deadline. It's an informal tender. It's allowed. It's up to the client. They'll make some excuse and then ask the question "How's it looking?" ...It comes back to reputation. The client is losing out. They're trying to pay no more than the minimum that they have to. If they didn't know the highest bid, then they might have bid even more. You're not getting the highest bid...I don't do it. I think that it's happening less and less. I've definitely seen it. But it's old school. They're a dying breed. We've become a much more diligent, compliant organisation. You've got to be so careful. Audits and regulation are much tighter.

Development agent for large multi-service practice

Just to be clear-there's not always a last call. There can be completely different cultures in different sectors.

Development agent for large multi-service practice 2

You can say on a late bid "My Board were in a meeting" ... They'll lose the trust of the market. It's a reflection on them. How can I trust them when we're dealing with them again? But it's hard to find out what really goes on. I don't think that those days are fully gone... There is an aspect that we can't control. It does go on. You don't get the last shout. You're told that it's not your turn. That's agents trying to control the market. We need to ensure that we don't rely on this type of practice...Information leakage is common. You never know if you're being led up the garden path.

Land director for volume housebuilder

Two respondents involved in land acquisitions for large housebuilders also referred to the possibility of being misled on the last call about the level of highest bid. They also mentioned that there were brokers 
who had or claimed to have relationships with selling brokers who could be approached by buyers, or who would approach buyers, looking for the opportunity to get the 'last call' in return for a fee.

I call it the 'last shout' rather than the 'last call'. It happens frequently...If we want the last shout, we'd use an intermediary agent from an external firm. The London boys all drink together. To get that inside information, we get them to talk to their mates...You can't always trust the information that you get. You don't know whether it's right and you don't know if anyone else is getting a call. You have to use your own judgement.

Land director for volume housebuilder

I've come across agents who say that they can do that (obtain the last call on a site being sold through another agent). At the end of the day it's hard to know if they've earned their fee. They can tell you anything.

Development director for volume housebuilder

Misleading indications of the highest price could also happen in the investment market.

It happens. Dishonest prices are sometimes stated. When you've got a special purchaser who scares off the competition. You need to create the illusion of interest, of competition.

Asset manager and former investment broker

In the investment market, the general lack of specialisation among brokers in buying or selling and a common propensity to specialise in a sector or geographical submarket seems to have created the conditions for a common 'currency' between brokers. Since it is typically the selling broker that has the valuable information (in the form of 'earlies', 'inside tracks' and 'last calls'), the main reciprocal 'payments' tend to be exchange of similar information in later transactions. The selling agent may also be rewarded for valuable information in terms of instructions for incremental advice. However, because of the different brokerage structure in the residential land market, this 'currency' for trading information was not present with selling agents. Given the fact that residential developers tend to buy without any representation by brokers and the large brokerage practices, in turn, tend to specialise in land sales, the incentives to exchange information (e.g. earlies and last calls) are not present to the same extent. However, there is evidence to suggest that selling agents of development land attempt to exchange information (e.g. inside track, last call) or a favourable recommendation to the seller in return for agreements to act as agent on the sale of the new homes when completed. There may even be a simple threat of exclusion from the sales process.

Identified by McNamara (1984), the practice of requiring an instruction on the new house sales seems to have persisted in the residential land market. This is despite the fact that most volume housebuilders prefer to sell their own developments without using third party residential brokers.

Often the primary motivation in selling a site is to be retained on the re-sales. There's far more money there. That's the big problem. It's an issue for the RICS. It's a conflict of interest. 
Introductory agent - sole practitioner

What they really want is the re-sales. In return, they're offering us exclusivity. It's one-toone. We don't like it. We don't need agents to sell our houses. They won't be incentivised. But it's a powerful necessity... That does happen a lot.

Development director for volume house builder

They want the re-sales. That's where the big money is involved. It can be massive. It's $1.25 \%$ of the GDV after affordable housing. It can be massive and sometimes they have to do next to no work for it. At the end of the day, it comes off the land price. The agents don't want it to be known.

Land director for volume house builder

Referring to a large multi-service practice who acted as selling agents for land owners but also had a large home sales division, one senior land director for a medium-sized volume house builder commented

You get a phone call "If you really want to buy this, then you need to instruct us to do the sales". It's as blunt as that. We have our in-house sales team. So, we end up paying sales agents for nothing. You have to do it if you want the land...Technically the land owner should know. Sometimes, when there's overage involved, the agents sell it as a monitoring fee... The other thing they do is they try to get you to buy other services. You don't get that much with the smaller firms. They don't have anything like the same range of services.

Senior land director - volume house builder

As noted above, a key point here is that land owners may not be aware that it is they who are effectively bearing the cost of, what McNamara (1984) labelled, a 'double reward' for the intro (when off-market) or selling agent (when on-market). Housebuilders will incorporate additional development costs associated with extra brokerage fees into their appraisals and adjust their land bid accordingly.

There was also evidence that, mainly for smaller off-market sites, the potential for ambiguity about the role of the intro agent could lead to double dipping (taking fees from the buyer and the seller) and fee sharing. There seemed to be two types of fee sharing. The first was when, in return for a share of their introduction fee, an agent representing the land owner sought out another agent to introduce the land to the buyer, even though a transaction price had already been informally agreed with the buyer. The seller's agent would then get a share of this fee with the buyer's agent effectively doing nothing for their share of the fee. The second involved a similar arrangement when the broker acting for the buyer involved an additional broker who would represent the land owner. The seller's broker would effectively contribute little to the transaction and pay a share of their fee to the buyer's broker.

Certain agents will only buy sites from certain agents. The acquisition agent gives half his fee back. It is not routine. It is not exceptional either. Are we routinely corrupt? I reckon it's just 10 or 15 per cent of transactions.

Introductory agent - sole practitioner (formerly with large multi-service firm) 
In the 1990s someone was always taking money for information. It still happens but it's few and far between now...There's an agent that I've dealt with and known for a long time. He's selling. He'll get an independent third party to come to you to act on your behalf. To cover myself, I always get a letter stating that the fee won't be given to anybody else. They've no problem signing the letter. It's quite rare. That's the grubbier part. I'd say it's 5\% that falls down as unethical or illegal. Most agents are fairly straight.

Senior land director for volume house builder

This material emerged in later interviews and was not discussed in the earlier ones. However, the emphasis put on compliance with the Bribery Act 2010 and other internal governance procedures that some volume housebuilders have in place made more sense when viewed in this context.

In the last 8-10 years, it's become more formal, more white, more regulated and more sophisticated. It's preventing agents giving inside tracks. The public sector processes have spilled over to the private sector. It's a sledgehammer to crack a nut. But the agents have to be seen as incorruptible. It would damage their reputation...It's still very unregulated. It's become more and more self-regulating.

Development director for volume housebuilder

Our standard instruction letter includes certain terms. The agent has to disclose their fee to the selling agent and ensure that their fee is disclosed to the land owner. We want to have a very clear paper trail. Fees ultimately come off the land price and often the land owner wants best value. If an agent introduces a site to us and brings in one of their mates to act for the land owner so that they get a share of the fee, that's untoward. It's being rooted out of the industry. We're trying to stamp that out. The Anti Bribery Act is very clear. The Bribery and Corruption Act...In the offer letters, we'll state all the fees. At the interviews with the land owner and their agent, we'll tell them how much the agents are being paid so that there's nothing untoward...You have to disclose everything internally. You must disclose everything to the hierarchy. It's controlled every step of the way.

Land director for volume housebuilder

It was clear from the interviews that large, listed volume house builders had placed increasing importance on compliance and procedures to eliminate unethical practices when acquiring sites. However, as the discussion above suggests, the payment of re-sale fees or fee payments to obtain the 'last call' does raise some ongoing concerns.

The paper started off with some statements about the perceived influence of brokers in terms of their ability to exercise market power. For the institutional commercial real estate investment market, some respondents provided vivid descriptions of the power of individual brokers to act as 'gatekeepers'.

Agents are hugely important. The higher up the risk curve you are, the more important they become. For core investors, they're extremely important...It's the only way that you can be sure that you're seeing what's on the market... There's definitely agents that we're scared of. [NAME DELETED] was feared. If you pissed him off, you would never get a deal from him again. He basically controlled the [Specific sector deleted] market. 
Institutional asset manager

For the City of London and West End office markets even in Manchester and Birmingham, the number of key participants is a very tight and small group. They'll try to control the information. If you're in that clique, you'll be privy to early information. If they're dominant in a niche market, they've got a lot of power. You'll want to keep them onside. There's stories of some powerful agents. I honestly don't know whether it's folklore or not.

Senior broker in multi-service real estate advisory firm

The last response by a senior, experienced broker indicates the difficulties for anyone outside of 'the market' of reaching definitive conclusions about the distinction between folklore and objective reality in this topic. Some respondents also pointed to the contingency of any market power. In particular, market power is likely to be contingent upon the level of competition for assets. When market conditions are subdued with limited competition for assets, selling brokers do not have the same gatekeeping power. This was also referred to above by one respondent who welcomed pressure from buyers as an indicator of positive market sentiment. Invariably, it was brokers who suggested that their power was limited. The size of the market and, more specifically the number of potential bidders, was also regarded as a restraint on the potential market power of small groups of brokers.

We're at the whim of the client. We like to play things straight. An agent has very little true power... The selling agent only has a lot of power in the right market conditions.

Broker working for specialist retail investment agency

There's half a dozen in each sector for large lot sizes...It's less prevalent for smaller lots sizes. It's just so diverse. For anything under $£ 10$ million, we have no idea who the buyer will be. There's lots of overseas. It's really the larger asset sizes where you get half a dozen agents operating and sharing information.

Senior broker in multi-service real estate advisory firm 2

The last point refers to the fact that in markets with lots of potential buyers, the value of an early from a selling broker tends to decrease as the size of the potential buyer pool grows and it becomes more difficult to identify the 'hot money'.

It was the diversity of the land market that was highlighted as a key factor limiting the market power of brokers in this context. Clearly, the dominance of the large global practices on the sell-side was a factor. However, the consensus was that the larger pool of buyers and sellers in the more geographically dispersed land market limited the power of agents despite intense competition for development land.

The competition for land is so fierce. I don't think that a particular agent can control much. Land is more powerful than the agents.

Development director for volume house builder 
You need to be close to the agents if you're buying and selling... There's not the same capacity to dominate a market like City offices or shopping centres in the land market. It's much more regionalised.

Development agent for large multi-service practice 2

Since most large sites were being sold by the large international practices, it was recognised that it was important to maintain good relationships with them

Individual agents aren't that powerful. [Firm names deleted], they're extremely influential. Nowadays, they're usually acting for land owners. You have to have good relationships with them. You can't mess them about. You can't let them down. If I haven't done my job properly - got the Board onside - and the deal falls through, there will be a big health warning. They could lose their client and they won't be recommending you when the next deal comes even though you might be the highest bidder...They're also powerful because they know what is coming. It's market intelligence. For us, it's about business planning.

Land director for volume house builder

The comments here are somewhat ambiguous. On the one hand, there was a consensus that it was not possible for relatively small networks of development agents to 'manage the market' to favour their own interests. On the other hand, it was clear that having good relationships with the leading brokerage firms was important in order to acquire housing land.

\section{Concluding Remarks}

The research discussed here is essentially exploratory and, as such, should be treated with some caution in terms of generalisation and quantification. In addition, there is a wide variation in ethical intensity between different types of behaviour. Opportunistic behaviours in commercial real estate brokerage can vary across a spectrum ranging from fairly harmless information leakage in the form of market gossip to criminal bribery. Adjectives such as unprofessional, unethical or corrupt used to describe opportunistic behaviours reflect the challenges of defining, identifying, measuring and investigating their prevalence. Because they are essentially concerned with morality, these concepts can be sometimes imprecise and relative and are often used with some indefinite qualifying adverbs such as 'mildly', 'fairly' or 'highly'. There can be subtle nuances. In one context, a self-interested, opportunistic behaviour such as collusion between intermediaries can generate gains for both intermediaries and principals in the form of faster transaction execution. In another context, the same behaviour can be used to optimistically bias the bid price of the buyer or reduce the price that would be paid to the seller.

Some of the practices recounted by respondents and recorded in the paper are likely to be exceptional, whilst others seem to be routine. Practices such as securing an instruction to act on re-sales as an 
informal condition of sale seem to have remained firmly embedded in a significant section of the residential land market and it seems unlikely that most land owners are aware that they are sometimes effectively paying for a 'double reward' to their broker. Although it is often only found in off-market sales for relatively small lots, they are also unlikely to be aware when they are also paying for the fee of an 'extra' broker unnecessarily brought into a transaction. Illegal activities seem to be extremely rare. Indeed, sometimes it is difficult to see who is harmed by self-interested behaviour. How is the seller harmed if their broker gives an early to a close friend? Indeed, the seller and buyer may even benefit from reduced execution risk.

Like many information intermediaries such as auditors and equity analysts, the literature review indicated that there have been fairly longstanding concerns about the potential of real estate brokers to exploit their informational advantages to generate rents. In this context, the source of rents and their quantity is contingent on how the brokerage sector operates in a specific market and the conditions in that market. In England, the lack of broker specialisation in buying and selling in the double-brokered, institutional real estate market in combination with the 'first past the post' broker appointment convention and the widespread use of (what can only be described as) a very informal tendering process have created a market structure where valuable market intelligence is commonly traded within broker networks.

However, other international commercial real estate markets have different institutional structures and practices. Often transactions are single brokered with only the seller having an agent. Sale by private negotiation rather than bidding through informal tender is standard in some markets. Each market structure would be expected to generate its own potential patterns of opportunistic behaviours. In the English residential land market, different brokerage structures have produced a different pattern of opportunistic behaviours and different approaches to extracting rents compared to the commercial real estate market. Even within the residential land market, large sites which tend to be single-brokered by large brokerage practices and sold by 'best bids' generate significantly different types of opportunistic behaviours compared to smaller sites which are often double-brokered by individual, independent 'intro' brokers and sold by private negotiation. As the interactionist model would predict, a range of internal and external variables will affect the extent to which brokers, buyers and sellers then behave opportunistically in transactions.

The sometimes inconsistent and contradictory perceptions and experiences of respondents could be due, to some extent, to self-reporting bias but it could also reflect heterogeneity of behaviours among individuals and sub-markets. Respondents sometimes referred to different practices in other submarkets, by other individual brokers or 'clubs' of brokers, by other firms and at different times. In the same way that different market and/or brokerage structures create different openings for 
opportunistic or unethical behaviours, the extent to which those openings will be exploited in concrete situations will be contingent upon heterogeneous situational and dispositional factors. As the model of the determinants of ethical outcomes suggested, these can include compliance cultures within (client and brokerage) firms, regulatory robustness, prevailing business norms, market conditions, the type of transaction, expected returns and risks as well as individual moral reasoning which can vary with gender, age, income, etc. Given significant heterogeneity in these determinants, sometimes inconsistent and contradictory experiences and perceptions of ethical behaviours should be expected.

It is debateable whether this research has major implications for or reflects failures in professional selfregulation. A number of respondents did identify some specific issues to which they believed the RICS should respond. Others expressed concern that the exposure of certain practices in this research could lead to increased market regulation. However, the main professional body to which many brokers belong (the RICS) has long placed a great deal of emphasis on ethical issues and managing the conflicts of interest that can occur in real estate markets. The vast majority of brokers are likely to be aware that practices such as 'the last call' or fee-sharing are ethically or professionally dubious. However, such practices are often difficult to observe and difficult to police. In addition, it is also important to acknowledge that the brokers are not the only RICS members involved in such practices where they occur. Many of the principals on both the buy side and sell side are themselves RICS members and are aware of unethical practices and some are encouraging them in their own self-interest. Put simply, principals (buyers and sellers) will often collude with brokers in unethical behaviour in order to attempt to ensure that they minimise the price paid or maximise the revenue. Indeed, the persistence of the market structure is likely to reflect the fact that a sufficient proportion of both principals and agents perceive that their interests are best served by it.

Where practices judged to be unethical, unprofessional and/or corrupt have become institutionalised in a specific market, removing them may require changes to the market institutional structures that have enabled them. The 'first past the post' convention facilitates broker rigging where transactions may become choreographed right down to the 'last call'. The importance of 'front-running' advantages, the reciprocity involved in earlies and last calls, the opaque market environment and the consolidation of the brokerage sector can reinforce the importance of small, close-knit broker networks. However, these networks can mutate into collusive cliques who dominate specific sub-markets where there are relatively small numbers of investors and intermediaries. At the very minimum, the 'first past the post' convention means that the buyer often does not get to choose their own broker. In turn, the informality in the 'bid bids' process facilitates the 'last call' and/or privately informed late bids. It is hard to see how informing late bidders of the minimum price that they need to bid to secure an asset can significantly benefit the seller. However, it is easier to see how it can benefit the seller's broker who will expect an equally valuable reciprocal 'favour'. At the same time, the experience of 'double dipping' 
by large global brokerage practices in the central London office market shows that recognition of a specific potential concern and the production of practical guidance by professional associations can be effective in acknowledging a specific problem and establishing unambiguous expectations about professional behaviour. A similar self-regulatory approach could be effective in discouraging the practices identified in this research. Governmental regulation can also be effective. Whilst not referred to by commercial real estate brokers, a number of volume house builders referred to increased emphasis on compliance following the Bribery Act 2010. The genesis of the Bribery Act can be traced back to the Poulson affair in the 1960s and 1970s - a political scandal closely related to unethical behaviours in real estate development.

Whilst a range of unethical practices have been identified in this research, it has not been possible to robustly assess their prevalence which, in turn, raises challenges in assessing their implications. As noted above, some seem to be uncommon, whereas others appear to be fairly routine. Whilst there are methodological challenges in researching unethical behaviours, systematic survey-based research could provide some further insights. Given that the UK commercial real estate market has been rated as the most transparent and best governed globally, there is certainly scope for similar work in other markets to explore the extent to which the interactions between market practices, regulation and other institutional structures generate different patterns of behaviour. Further research on the nature, prevalence, causes and effects of unethical behaviours in brokerage models can potentially be approached using a wide array of quantitative and qualitative research methods. Whilst there have been several hedonic studies that have attempted to measure the impact of brokerage structures on prices in the commercial real estate market, it is surprising that there has been little attempt to replicate Ling et al's (2018) striking results. The effects of brokerage structures on a range of other transaction costs such as buying and selling times and execution risk could also be investigated. Finally, relying often upon experimental techniques used in behavioural finance, ethical issues in real estate markets have been (mainly implicitly) addressed in research on client influence in real estate appraisals. Similar techniques are widely applied to examine the determinants of ethical behaviour in business and management studies and there is scope for their application in the real estate brokerage sector. 


\section{References}

Adams, D., Leishman, C. and Watkins, C. 2012. Housebuilder networks and residential land markets. Urban Studies, 49, 4, 705-720.

Agarwal, S., He, J., Sing, T.F. and Song, C. 2019. Do real estate agents have information advantages in housing markets? Journal of Financial Economics, 134, 3, 715-735.

Ahmed, K., Chung, K. and Eichenseher, J. 2003. Business Students' Perceptions of Ethical and Moral Judgement: A Cross Cultural Study, Journal of Business Ethics, 43, 89-102

Archer, T. and Cole, I. 2016. Profits before Volume? Major Housebuilders and the Crisis of Housing Supply, Centre for Regional Economic and Social Research (CRESR) Report, Sheffield Hallam University.

Bloomenthal, H.S. 1960. The Case of the Subtle Motive and the Delicate Art-Control and Domination in Over-the-Counter Securities Markets. Duke Law Journal, 196-220.

Booth, R. 2018. Revolving door between councils and lobbyists raises transparency issues, The Guardian, 30 April 2018.

Booth, R. and Jones, A. 2018. Homebuilders' lobbyist pushed council leader to 'sort' and speed planning, The Guardian, 13 September 2018.

Brand, V., 2009. Empirical business ethics research and paradigm analysis. Journal of Business Ethics, 86, 4, 429-449.

Brown, M. and Treviño, L. 2006. Ethical leadership: A review and future directions. The Leadership Quarterly, 17, 6, 595-616.

Chan, Y.S. 1983. On the positive role of financial intermediation in allocation of venture capital in a market with imperfect information. The Journal of Finance, 38, 5, 1543-1568.

Collins, J.D., Uhlenbruck, K. and Rodriguez, P. 2009. Why firms engage in corruption: A top management perspective. Journal of Business Ethics, 87, 1, .89-108.

Cypher, M., Price, S.M., Robinson, S. and Seiler, M.J. 2018. Price signals and uncertainty in commercial real estate transactions. The Journal of Real Estate Finance and Economics, 57. 2, 246263.

Delcoure, N. and N. G. Miller. 2002. International residential real estate brokerage fees and implications for the US brokerage industry. International Real Estate Review, 5, 12-39.

Devaney, S., McAllister, P., Livingstone, N. and Nanda, A. 2017. Institutional Convergence in Real Estate Markets: A Comparative Study of Brokerage Models and Transaction Costs, Journal of Real Estate Literature, 25, 169-188.

Devaney, S., Livingstone, N., McAllister, P. and Nanda, A. 2019. Capitalization rates and transaction activity in international office markets: A global perspective. Global Finance Journal, 42, p.100469.

Devaney, S. and Scofield, D., 2017. Do 'foreigners' pay more? The effects of investor type and nationality on office transaction prices in New York City. Journal of Property Research, 34, 1, 1-18. 
DiMaggio, P. and Powell, W. 1983. The iron cage revisited: Institutional isomorphism and collective rationality in organizational fields. American Sociological Review, 48, 2, 147-160.

Gert, B. 1984. Moral theory and applied ethics. The Monist, 67, 4, 532-548.

Graham, G., 2004. Eight theories of ethics. Psychology Press.

Granitz, N. 2003. Individual, social and organizational sources of sharing and variation in the ethical reasoning of managers. Journal of Business Ethics, 42, 2, 101-124.

Gubrium, J. and Holstein, J. 2001. Handbook of Interview Research: Context \& Method, SAGE, London

Guest, G., Bunce, A. and Johnson, L. 2006. How Many Interviews Are Enough? An Experiment with Data Saturation and Variability, Field Methods, 18, 59-82

Halbert, L. and H. Rouanet. 2014. Filtering risk away: Global finance capital, transcalar territorial networks and the (un)making of city-regions: An analysis of business property development in Bangalore, India. Regional Studies, 48, 3, 471-484.

Halpern, J.J. 1996. The effect of friendship on decisions: Field studies of real estate transactions. Human Relations, 49, 2, 1519-1547.

Hardin, W., Johnson, K. and Wu, Z. 2009. Brokerage intermediation in the commercial property market. Journal of Real Estate Research, 31, 4, 397-420.

Hatfield, J.W., Kominers, S.D., Lowery, R. and Barry, J.M. 2019. Collusion in markets with syndication. Harvard Business School Entrepreneurial Management Working Paper, (18-009).

Hayman, A. 2014. Investment agents unveil code to curtail 'double dipping', Property Week, 14 March 2014.

Healey, P. ed., 2006. Making strategic spatial plans. Routledge.

Hodgson, G., 2002. The evolution of institutions: an agenda for future theoretical research. Constitutional Political Economy, 13, 2, 111-127.

Knorr-Cetina, K.D. 2012. What is a financial market? Global markets as microinstitutional and posttraditional social forms, In Knorr-Cetina, K.D. and A. Preda, A. (eds.) The Oxford handbook of the sociology of finance. Oxford: Oxford University Press.

Leslau, N. 2014, Double running and honest brokers who say 'don't do the deal', Property Week, 14 March 2014.

Levitt, S.D. and Syverson, C. 2008. Market distortions when agents are better informed: The value of information in real estate transactions. The Review of Economics and Statistics, 90, 4, 599-611.

Ling, D.C., Naranjo, A. and Petrova, M.T. 2018. Search costs, behavioral biases, and information intermediary effects. The Journal of Real Estate Finance and Economics, 57, 1, 114-151.

Martin, M. 1981. Professional and ordinary morality: A reply to Freedman. Ethics, 91, 4, 631-633.

Mayer, D. M., Kuenzi, M., Greenbaum, R., Bardes, M., and Salvador, R. 2009. How low does ethical leadership flow? Test of a trickle-down model. Organizational Behavior and Human Decision Processes, 108, 1-13. 
McAllister, P., Hughes, C. and Gallimore, P. 2008. Principal-agent Issues in Asset Acquisition: UK Institutions and their Investment Agents. Journal of Property Research., 25, 4, 269-283.

McFall, L. 1987. Integrity. Ethics, 98,1, 5-20.

McNamara, P. 1984. The role of local estate agents in the residential development process, Land Development Studies, 1, 101-112.

Nanda, A., Clapp, J.M. and Pancak, K.A. 2016. Do laws influence the cost of real estate brokerage services? A state fixed effects approach. Real Estate Economics, 44, 4, 918-967.

Nelen, H. 2008. Real estate and serious forms of crime. International Journal of Social Economics, 35, 10, 751-762.

Pincus, A. 2011. Eastdil Secured: A \$15 billion enigma, The Real Deal, 3 October 2011.

Quinn, D. and Jones, T. 1995. An agent morality view of business policy. Academy of Management Review, 20, 1, 22-42.

Randall, D. and Gibson, A. 1990. Methodology in Business Ethics Research: A Review and Critical Assessment, Journal of Business Ethics, 9, 4, 457-471.

Rodriguez, P., Uhlenbruck, K. and Eden, L. 2005. Government corruption and the entry strategies of multinationals. Academy of Management Review, 30, 2, 383-396.

Rutherford, R C, Springer, T M and Yavas, A. 2005. Conflicts between principals and agents: Evidence from residential brokerage. Journal of Financial Economics, 76, 3, 627-65.

Rutherford, R., Springer, T. and Yavas, A. 2007. Evidence of Information Asymmetries in the Market for Residential Condominiums. Journal of Real Estate Finance and Economics. 35, 1, 23-38.

Schein, E. 1984. Coming to a new awareness of organizational culture. Sloan Management Review, 23, 3-16.

Scofield, D. 2013. Time to Completion Liquidity in Commercial Real Estate Investment: 2000-2008. Journal of European Real Estate Research, 6, 1, 34-47.

Scofield, D, 2018. Global cities, local practices: Intermediation in the commercial real estate markets of New York City and London. In Global City Makers. Edward Elgar Publishing.

Tenbrunsel, A. and Smith-Crowe, K. 2008. 13 ethical decision making: Where we've been and where we're going. The Academy of Management Annals, 2, 1, 545-607.

Trevino, L. 1986. Ethical Decision Making in Organizations: A Person Situation Interactionist Model, The Academy of Management Review, 11, 601-617.

Van de Bunt, H. and van Wingerde, K. 2015. We are all going to be rich. A case study of the Dutch real estate fraud case. In: The Routledge Handbook of White-Collar and Corporate Crime in Europe, 304-317.

Vanberg, V. 1986. Spontaneous market order and social rules: a critical examination of FA Hayek's theory of cultural evolution. Economics \& Philosophy, 2, 1, 75-100. 
Walumbwa, F. O., Avolio, B. J., and Zhu, W. 2008. How transformational leadership weaves its influence on individual job performance. Personnel Psychology, 61, 793-825.

Wiggins, D. 2006. Ethics: Twelve lectures on the philosophy of morality. Harvard University Press.

Windsor, C. and Ashkansay, N. 1995. The effect of client management bargaining power, moral reasoning development and belief in audit, Accounting, Organizations \& Society, 20, 7-8, 701-21

Yavas, A. and Colwell, P. 1999. Buyer Brokerage: Incentive and Efficiency Implications. Journal of Real Finance and Economics, 18, 3, 257-77

Zorn, T and Larsen, J. 1986. The Incentive Effects of Flat-Fee and Percentage Commissions for Real Estate Brokers. Journal of American Real Estate and Urban Economics Association, 14, $146-57$ 


\section{Appendix 1}

'Double dipping'

'Double running'

'Early'

'Hot money'

'Inside track'

'Landing lights'

'Last call'

Last shout'

'One-to-one'

'Off-market'

'On-market'

'Ramping'

'Runner'

\section{Glossary of Brokerage Terms}

Typically this is the practice of different individuals within the same brokerage firm representing the buyer and the seller in a transaction. It is also termed dual agency.

See 'Double dipping'.

Provision of advanced information by selling agent to a selected buying agent or buyer about land or property that will imminently be offered for sale. A 'genuine early' can be of significant value to the buying agent since it enables them to introduce the property to the most likely buyer before competing buying agents are aware that it is for sale.

Essentially, this is a phrase to describe the marginal investor(s). The marginal investor tends to be the investor who has been making the highest bids for similar assets and setting the asset's price.

Provision of inside information by the seller's agent to an interested buyer or their agent. Such information could include private advice on the seller's price expectations, preferences and/position of the seller and the identity and level of interest from competitors in the land or property.

See 'Last call'

Typically submitted after the bid deadline, this is an exclusive, informal opportunity to pre-empt the highest submitted bid in a competitive tendering process.

See 'Last call'

Opportunity to negotiate exclusively the terms of an acquisition of land or property in a non-competitive process.

See 'One-to-one'

Land or asset is marketed in the standard way and sold in a 'best bids' competitive tendering process.

The process whereby a buying agent encourages their client to increase their bid. This typically occurs through influencing the inputs into an appraisal e.g. incorporating optimistic estimates of Market Rents, exit yields and/or voids.

An agent that does not represent a seller or buyer directly. Typically, having identified a scheme that may be available for sale, they will approach agents who have established relationships with principals and share an introductory fee.

'Sharpen your pencil' Suggestion from the seller or their agent that an interested buyer change the assumption(s) in the appraisal model to generate an increased estimate of value.

Essentially, this is a rumour among brokers. In the US, a whisper price is industry vernacular for privately communicated and generally confidential intelligence about the likely sale price or the seller's expected price. 
